\title{
Dexamethasone-loaded scaffolds prepared by supercritical-assisted phase inversion
}

\author{
Ana Rita C. Duarte*, João F. Mano, Rui L. Reis \\ 3B's Research Group - Biomaterials, Biodegradables and Biomimetics, University of Minho, \\ Headquarters of the European Institute of Excellence on Tissue Engineering and Regenerative Medicine, AvePark, 4806-909 Taipas, Guimarães, Portugal \\ IBB - Institute for Biotechnology and Bioengineering, PT Government Associated Laboratory, Guimarães, Portugal
}

Received 30 July 2008; received in revised form 28 November 2008; accepted 13 January 2009

\begin{abstract}
The aim of this study was to evaluate the possibility of preparing dexamethasone-loaded starch-based porous matrices in a one-step process. Supercritical phase inversion technique was used to prepare composite scaffolds of dexamethasone and a polymeric blend of starch and poly(L-lactic acid) (SPLA) for tissue engineering purposes. Dexamethasone is used in osteogenic media to direct the differentiation of stem cells towards the osteogenic lineage. Samples with different drug concentrations (5-15 wt.\% polymer) were prepared at 200 bar and $55^{\circ} \mathrm{C}$. The presence of dexamethasone did not affect the porosity or interconnectivity of the polymeric matrices. Water uptake and degradation studies were also performed on SPLA scaffolds. We conclude that SPLA matrices prepared by supercritical phase inversion have a swelling degree of nearly $90 \%$ and the material presents a weight loss of $25 \%$ after 21 days in solution. Furthermore, in vitro drug release studies were carried out and the results show that a sustained release of dexamethasone was achieved over 21 days. The fitting of the power law to the experimental data demonstrated that drug release is governed by an anomalous transport, i.e., both the drug diffusion and the swelling of the matrix influence the release of dexamethasone out of the scaffold. The kinetic constant was also determined. This study reports the feasibility of using supercritical fluid technology to process in one step a porous matrix loaded with a pharmaceutical agent for tissue engineering purposes.
\end{abstract}

(C) 2009 Acta Materialia Inc. Published by Elsevier Ltd. All rights reserved.

Keywords: Supercritical fluids; PLLA; Drug delivery; Tissue engineering; Phase inversion

\section{Introduction}

Tissue engineering is a promising therapeutic approach that combines cells, biomaterials, and bioactive compounds $[1,2]$. The emerging next generation of engineered tissues relies on the development of loaded scaffolds containing bioactive molecules in order to control the cellular function (e.g. growth or differentiation factors) or to act on the surrounding tissues (e.g. drugs such as anti-inflamma-

\footnotetext{
"Corresponding author. Address: 3B's Research Group - Biomaterials, Biodegradables and Biomimetics, University of Minho, Headquarters of the European Institute of Excellence on Tissue Engineering and Regenerative Medicine, AvePark, 4806-909 Taipas, Guimarães, Portugal. Tel.: +351253 510900; fax: +351253510909.

E-mail address: aduarte@dep.uminho.pt (Ana Rita C. Duarte).
}

tory agents or antibiotics) $[3,4]$. Hence, the strategy is to mimic matrix and provide the necessary information or signaling for cell attachment, proliferation and differentiation to meet the requirement of dynamic reciprocity for tissue engineering. This justifies the importance of drug delivery in tissue engineering applications $[5,6]$.

Small molecular weight drugs that control proliferation and differentiation of cells can be incorporated into biodegradable scaffolds to induce cellular differentiation and tissue remodeling. The scaffold therefore plays an important role not only as a physical support but also in the cell proliferation and differentiation [7]. Dexamethasone is a relevant bioactive compound to be used in bone tissue engineering applications. This drug is used in osteogenic media to direct the differentiation of stem cells towards 
the osteogenic lineage [8-10]. A wide variety of materials has been used for the preparation of scaffolds, from metals to ceramics and polymers. Synthetic biodegradable polymers have been widely used for tissue engineering. However, natural polymers have unique, intrinsic properties that make them appealing to be used as scaffolds [11]. Natural polymers are in general non-toxic, even in large concentrations, mucoadhesive, biocompatible, and biodegradable [11-13].

Starch-based polymers have been studied in our group for a wide range of bone-related therapy applications, ranging from tissue engineering scaffolds [14-17], to bone cements $[18,19]$ and drug delivery systems $[20,21]$. Their natural origin, together with their mechanical properties and biocompatibility, support the potential of starch-based materials in the biomedical field. Our group has reported the success of starch-based microparticles, from starchpoly(L-lactic acid) (SPLA), to act as controlled delivery devices [22]. SPLA microparticles loaded with corticosteroids were able to release the drug up to 30 days.

One of the most important stages of tissue engineering is the design and processing of a porous 3D structure, with high porosity, high interconnectivity and uniform distribution. Conventionally, three-dimensional structures can be obtained by processes such as solvent casting-particle leaching [23], freeze-drying-particle leaching [24], thermally induced phase separation [25], compression moulding [26], injection moulding [27], extrusion [28], foaming [29], wet spinning [30], electrospinning [31], among others [32]. The main disadvantages of these methods are the use of large quantities of organic solvents or high temperatures. Supercritical fluids have been proposed as excellent alternatives to the conventional processes for polymer processing [3335].

The supercritical-assisted phase inversion method is one of the proposed alternatives to reduce the use of large quantities of organic solvents. Different techniques have been proposed for the preparation of scaffolds for tissue engineering, namely gas foaming or phase inversion [36]. Gas foaming takes advantage of the plasticizing properties of carbon dioxide. In this technique, the polymer is exposed to carbon dioxide, which plasticizes it by reducing the glass transition temperature or melting point. On venting the $\mathrm{CO}_{2}$ by depressurization, thermodynamic instability causes supersaturation of the carbon dioxide dissolved in the polymer matrix and hence nucleation of cells occurs [37]. This technique is limited by the high glass transitions of the crystalline polymers and is therefore more common to amorphous polymers.

The phase inversion method involves casting of a polymer solution onto an inert support followed by immersion of the support with the cast film into a bath filled with a non-solvent for the polymer. The contact between the solvent and the non-solvent causes the solution to be phaseseparated. Several advantages exist if the non-solvent used is a supercritical fluid. One of the most important advantages of the use of carbon dioxide is the fact that simply by tuning the processing conditions, i.e. pressure and temperature, one can tailor the final structure of the product. Additionally, when carbon dioxide is used as a non-solvent a subsequent drying step is avoided and the porous structure obtained is a dry product free of any residual solvent.

Carbon dioxide is the most commonly used supercritical fluid as it has mild critical parameters, it is environmentally benign, non-toxic, non-flammable, non-corrosive, ready available and inexpensive. Its elimination and the recovery of final products are easier (no residue is left and a dry solid product is easily obtained, just by controlling the pressure), leading to processes with less energy consumption [38].

The use of carbon dioxide as a non-solvent for phase separation has been successfully reported in the literature, for example for PLLA [39,40], PMMA [41], Nylon 6 [42], PS [43], cellulose acetate $[44,45]$, polysulfone $[46,47]$ and polycarbonate/PEG [48]. Recently we have proposed the use of a supercritical-assisted process for the preparation of scaffolds from natural sources [49]. A starch-based blend (SPLA) was successfully processed by supercritical-assisted phase inversion method.

To our knowledge the use of a supercritical phase inversion technique for the preparation of composite matrices loaded with a bioactive agent is for the first time reported in this work. In this study, the possibility of preparing in a one-step process a porous matrix loaded with an active compound is evaluated. This methodology could open other possibilities of developing substrates for tissue engineering or bioengineering applications, where processing of biomaterials and incorporation of bioactive agents are combined using supercritical fluid technologies.

\section{Experimental procedure}

\subsection{Materials}

A commercial blend of starch and poly-(L-lactic acid) (SPLA 50:50) was supplied by Novamont. Dexamethasone (CAS 50-02-2, 98\% purity) was purchased from Sigma and chloroform, (CAS 67-68-5, 99.9\% purity) was purchased from Vaz Pereira. Carbon dioxide (99.998 mol.\%) was supplied by Air Liquide. All chemicals were used with no further purification.

\subsection{Supercritical-assisted phase inversion process}

The phase inversion experiments were carried out in an apparatus specially designed and built for this work. The set up is schematically presented in Fig. 1 [49].

SPLA 50:50 is mixed with dexamethasone and dissolved in chloroform. This procedure was performed separately for each of the ratios of bioactive agent and polymer (5, 10 or $15 \%$ wt./wt. (dexamethasone:polymer). In each experiment a small amount (ca. $2 \mathrm{ml}$ ) of the polymer solution is loaded in a stainless steel cap $2 \mathrm{~cm}$ in diameter, which is placed inside the high pressure vessel. The vessel is heated (to $55^{\circ} \mathrm{C}$ ) by means of an electric thin band hea- 


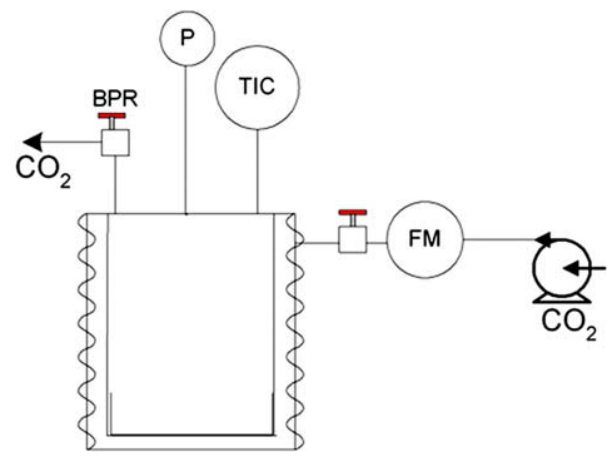

Fig. 1. Schematic diagram of the high pressure phase inversion apparatus ( $\mathrm{P}$, pressure transducer; TIC, temperature controller; FM, flowmeter; $\mathrm{BPR}$, back pressure regulator).

ter (OGDEN) connected to a temperature controller that maintains temperature within $\pm 1^{\circ} \mathrm{C}$ (TC). Carbon dioxide is pumped into the vessel, at a constant flow rate of $5 \mathrm{~g}$ $\min ^{-1}$, using a high pressure piston pump (P-200A Thar Technologies) until the operational pressure (200 bar) is attained. The pressure inside the vessel is measured with a pressure transducer $(\mathrm{P})$. The system was closed for 45 min to allow the occurrence of phase separation. Afterwards the system is flushed for another $45 \mathrm{~min}$, with a stream of carbon dioxide at very low flow rate $\left(5 \mathrm{~g} \mathrm{~min}^{-1}\right)$, in order to ensure complete drying of the scaffolds. The flow is regulated by a flow meter (FM - Siemens, SITRANS FC MASS FLO MASS2100). The outflow is regulated by a back pressure valve (Go Inc., USA).

\subsection{Scaffold characterization}

\subsubsection{Scanning electron microscopy}

Samples of the scaffolds prepared were observed by a Leica Cambridge S360 scanning electron microscope (SEM). The matrices were fixed by mutual conductive adhesive tape on aluminium stubs and covered with gold using a sputter coater.

\subsubsection{Micro-computed tomography (micro-CT)}

The inner structure, porosity and interconnectivity were evaluated by micro-computed tomography using a Scanco 20 equipment (Scanco Medicals, Switzerland) with penetrative X-rays of $40 \mathrm{keV}$. The X-ray scans were acquired in high-resolution mode $(39.39 \mu \mathrm{m})$. CT Analyser ${ }^{\circledR}$ (SkyScan, Belgium) was used to visualize the 2D X-ray sections images of the scaffolds.

\subsubsection{Fourier transform infrared analysis (FTIR)}

This was performed to the scaffolds loaded with dexamethasone. Spectra were recorded at 32 scans with a resolution of $2 \mathrm{~cm}^{-1}$ (Shimadzu - IRPrestige 21).

\subsection{Water uptake and degradation}

The swelling capability of the matrices prepared was accessed by measuring the water uptake of the samples for a period up to 22 days. Scaffolds of SPLA 50:50 prepared by supercritical phase inversion were weighed and immersed $10 \mathrm{ml}$ of an isotonic solution at $\mathrm{pH}$ 7.4. The samples were placed in a water bath at $37^{\circ} \mathrm{C}$. After predetermined periods of time (1, 3, 7, 14 and 22 days) the samples were weighed in order to determine the water uptake of the scaffolds.

Water uptake was determined using the following equation:

$\%$ water uptake $=\frac{w_{w}-w_{i}}{w_{i}} \times 100$

where $w_{w}$ is the weight of the wet sample and $w_{i}$ is the weight of the initial sample.

After each time period the samples were dried and weighed to determine the weight loss, which was calculated according to the equation:

$\%$ weight loss $=\left|\frac{w_{f}-w_{i}}{w_{i}}\right| \times 100$

where $w_{f}$ is the final weight of the dry sample after immersion and $w_{i}$ is the initial weight of the sample.

The $\mathrm{pH}$ of each solution was also measured in order to determine the effect of polymer degradation on the acidity of the medium.

The data presented are the result of the average of at least five measurements.

\subsection{In vitro release studies}

Dexamethasone-loaded SPLA scaffolds were weighed (average weight $9 \pm 0.3 \mathrm{mg}$ ) and suspended in $10 \mathrm{ml}$ of phosphate buffer solution stirred at $60 \mathrm{rpm}$ at $37^{\circ} \mathrm{C}$. Aliquots of $500 \mu \mathrm{l}$ were withdrawn in predetermined time intervals and the same volume of fresh medium was added to the suspension. The samples were analysed by UV-vis spectroscopy at $242 \mathrm{~nm}$ (Shimazu UV 1601). The results presented are an average of three measurements. Calculations of the amount of drug released took into account the replacement of aliquots with fresh medium.

\section{Mathematical modelling of drug release}

Knowledge of the mass transport mechanisms and the kinetics of the drug release is essential for the design of new drug delivery systems. Several models from simple empirical or semi-empirical to more complex mechanistic theories have been proposed to describe drug release from delivery systems.

Higuchi derived a very simple empirical equation (3) describing the rate of release of solid drugs under pseudo-steady-state assumptions [50]. This relationship demonstrates the linearity between the release rate and the square root of time:

$\frac{M_{t}}{M_{\infty}}=K \sqrt{t}$ 
where $M_{\infty}$ is the cumulative amount of drug released at infinite time and $K$ is a kinetic constant [51]. An exact solution of Fick's law of diffusion describes the proportionality between the fractional amount of drug released and the square root of time and can be written in a similar way to Eq. (1). The validity of these equations is, however, only valid up to $60 \%$ of the total amount of drug $\left(M_{\infty}\right)$.

Although both Higuchi and Fick equations have the same mathematical expression and describe the same behaviour, there is a major distinction between their assumptions. Nevertheless, in both cases diffusion is the dominating mass transport mechanism and the drug release is diffusion-controlled.

Another case is one where the drug release rate is independent of time, i.e., it corresponds to a zero-order kinetics. Many situations of release processes fall between these cases, the Fickian diffusion and the zero-order kinetics. An heuristic equation, known as power law, that translates this behaviour, can be written as $[52,53]$ :

$\frac{M_{t}}{M_{\infty}}=k t^{n}$

where $k$ is a constant and $n$ is the diffusional exponent, which is indicative of the transport mechanism. Like Eq. (3), this relationship is only valid for the first $60 \%$ of the drug released.

\section{Results and discussion}

\subsection{Synthesis of dexamethasone-loaded SPLA scaffolds}

In this study the possibility of preparing dexamethasone-loaded SPLA scaffolds with potential application in tissue engineering using supercritical fluid technology was evaluated. Supercritical-assisted phase inversion technique presents some advantages over the conventional phase inversion process, namely the fact that porosity and interconnectivity are induced in the samples at the same time that the material is precipitated from the organic solvent. Furthermore, the material is recovered in the dry state, which avoids the use of any additional drying steps, reducing the processing energy consumption and leading to more efficient processes. From the matrix prepared, smaller cylindrical samples were cut with an average height of $1.7 \mathrm{~mm}$ and an average diameter of $4 \mathrm{~mm}$. Scaffolds with three different drug concentrations were prepared, namely
5, 10 and $15 \%$ wt./wt. (drug:polymer). Samples were prepared at $55^{\circ} \mathrm{C}$ and 200 bar and the morphology of the matrices was evaluated by SEM analysis (Fig. 2).

The synthesis of SPLA scaffolds loaded with dexamethasone leads to structures with similar morphologies to the unloaded scaffolds. Therefore, the impregnation of dexamethasone does not seem to produce significant changes in the morphology of the polymeric structures. The SPLA matrices obtained by supercritical-assisted phase inversion are bicontinuous structures characterized by a rough surface where micropores and macropores are visible. Such particular microstructure enhances the transport properties within the structure and could also encourage cell attachment and proliferation. The matrices are also characterized by a highly interconnected porous structure.

Micro-computed tomography allows a better visualization of the inner structure of the matrices prepared. An example of the 3D model of a loaded SPLA matrix prepared by supercritical-assisted phase inversion method is shown in Fig. 3.

Fig. 3a demonstrates that the porous structure exhibits a significant porosity and interconnectivity is throughout all the volume of the sample. The porosity of the sample was calculated to be $\sim 66 \%$. The representative $2 \mathrm{D}$ slice in Fig. $3 \mathrm{~b}$ shows the macropores $(\sim 200 \mu \mathrm{m})$ and the micropores (ranging from 20 to $50 \mu \mathrm{m}$ ) of the sample.

The presence of dexamethasone in the scaffolds was confirmed by the FTIR analysis. Fig. 4 shows the spectra for the scaffolds of SPLA and SPLA loaded with dexamethasone. The characteristic peaks of dexamethasone at 900 and $1650 \mathrm{~cm}^{-1}$ can also be observed in the scaffolds prepared with the different amounts of drug. This confirms the presence of drug in the matrix. The relative intensity of these peaks with respect to the SPLA bands increases with increasing dexamethasone content.

\subsection{Water uptake and degradation studies}

Both the hydration degree and the degradation behaviour are the most important properties of the materials when they are aimed to be used in biomedical or environmental applications, as their lifetime will be governed by these two processes which are intimately correlated. For biodegradable polymers degradation occurs as a result of natural biological processes or other factors such as hydrolysis. Additionally, the drug release rate is mostly influ-
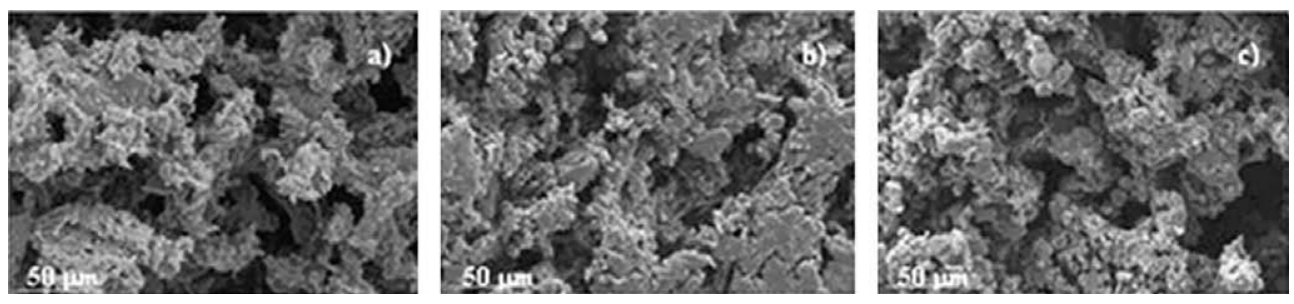

Fig. 2. SEM images of the scaffolds prepared at 200 bar and $55^{\circ} \mathrm{C}$ with $15 \%$ polymer in solution: (a) dexamethasone 0 wt. $\%$; (b) dexamethasone $5 \mathrm{wt} . \%$; and (c) dexamethasone $15 \mathrm{wt} . \%$. 

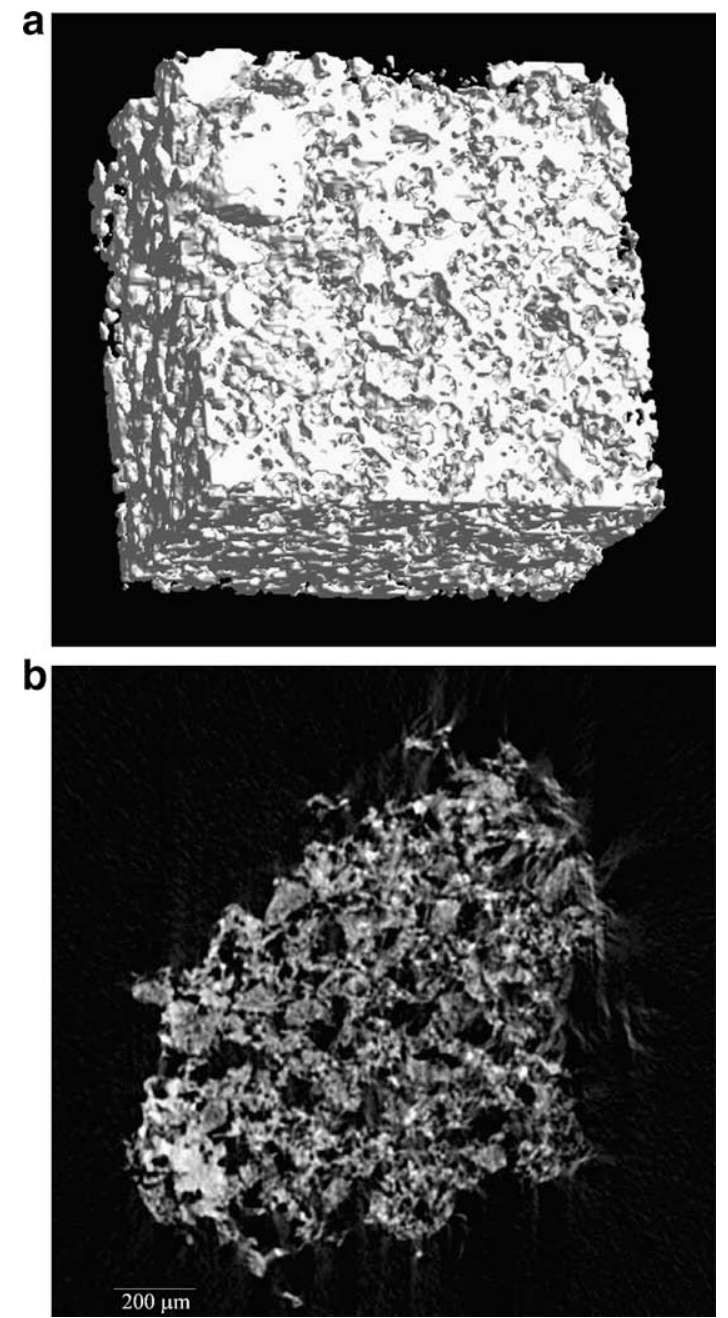

Fig. 3. Representative micro-CT images of SPLA matrix prepared at 200 bar and $55^{\circ} \mathrm{C}$ (10wt.\% dexamethasone): (a) 3D model and (b) 2D model.

enced by two factors: the diffusion of the drug out of the scaffold and the water uptake of the polymeric matrix. For these reasons and for the preparation of systems for controlled release applications, the knowledge of water uptake and degradation is relevant.

In order to evaluate the swelling of the porous matrix, water uptake studies on unloaded SPLA scaffolds were carried out. Fig. 5 presents the percentage of water uptake of the matrix as a function of time.

A great fraction of the water uptake corresponds to the water that is found in the macropores of the scaffolds. The scaffolds obtained by supercritical-assisted phase inversion exhibit different water uptakes, as compared to samples obtained by other processing techniques reported in the literature $[54,55]$. This is probably due to the high porosity and interconnectivity achieved with this method. Previous studies from our group, on starch-based polymers, have shown that the difference in water uptake and degradation of scaffolds from the same polymer might be due to the different processing technologies [56]. The properties of the $3 \mathrm{D}$ scaffold have a more relevant role in the swelling and

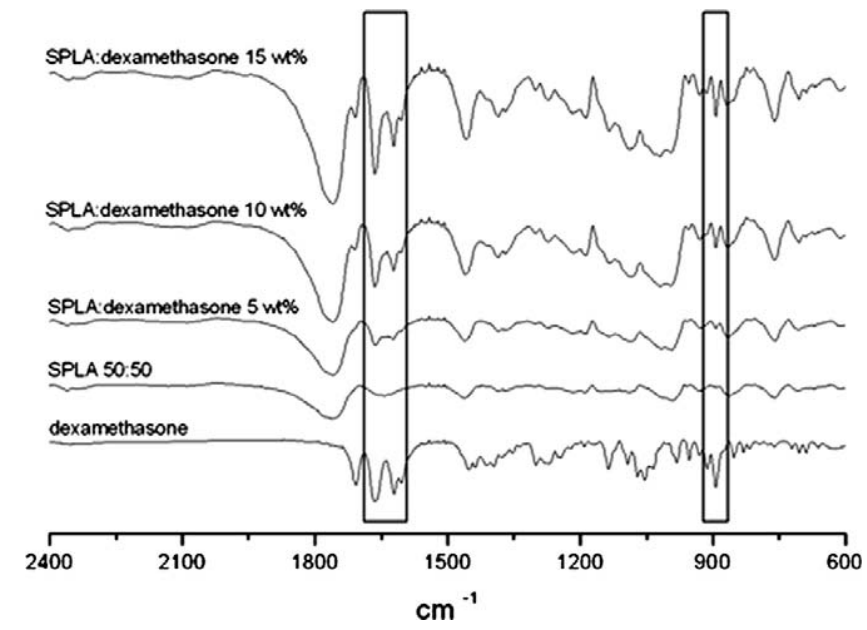

Fig. 4. FTIR spectra of dexamethasone, SPLA 50:50, dexamethasoneloaded SPLA at $5 \mathrm{wt} . \%, 10 \mathrm{wt} . \%$ and $15 \mathrm{wt} . \%$.

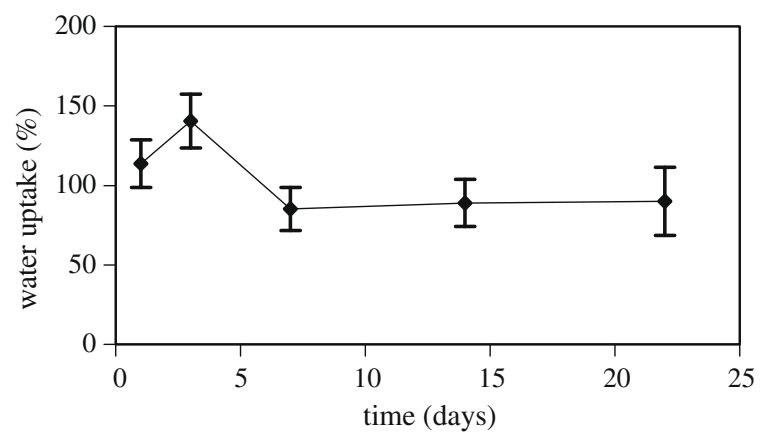

Fig. 5. Water uptake profile of SPLA 50:50 porous scaffolds prepared by supercritical phase inversion.

degradation of the matrix than the polymer itself. The limit value for the water uptake should be regarded as a result of two complementary phenomena: the intrinsic water uptake capability of the material (related to the chemical composition and crystallinity) and the degradation history of the material. These phenomena are somewhat inter-related. This is the main reason why the water uptake should be discussed along with the weight loss behaviour [57]. Water uptake experiments give some indication also on the degradation of the sample itself. We can observe in Fig. 4 that the water uptake increases from the first to the third day but afterwards there is a decrease in the swelling of the polymer. This can be due to the degradation of the material. During degradation the mass of material may undergo changes and these changes can be monitored by comparison of the mass before and after the degradation period. Fig. 6 shows the weight loss of the material as a function of time.

After implantation, biomaterials interact with surrounding fluids by first absorbing water, which initiates their degradation process. The absorption of water makes the material more flexible and might cause dimensional changes. Moreover, higher water absorption usually accel- 


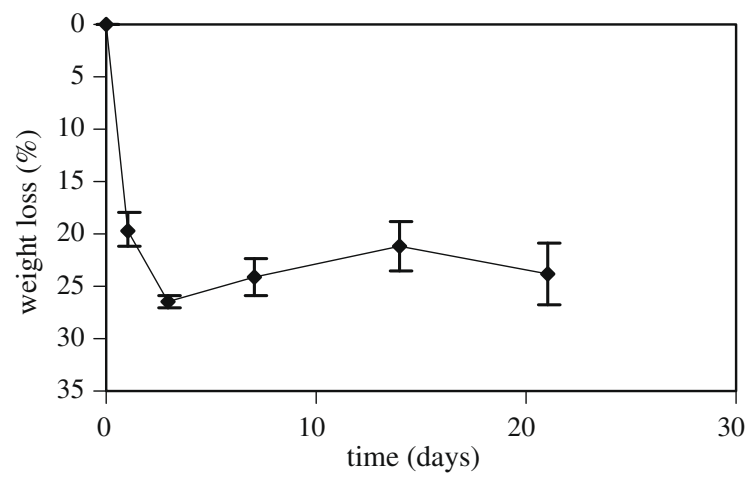

Fig. 6. Weight loss profile of SPLA 50:50 porous scaffolds prepared by supercritical phase inversion.

erates the hydrolysis process. The effect of porosity and water uptake in the mechanical and viscoelastic properties of the SPLA scaffolds was analysed in another work [58]. The scaffolds' porosity will have direct influence in the ease of retention and access of the degradation solution in the bulk of the material, which will therefore influence their degradation behaviour. The weight loss of the SPLA samples prepared by supercritical-assisted phase inversion is reduced by about $25 \%$ in 3 days. This weight loss is mainly due to the leaching of small particles that can detach from the scaffold as it is immersed in water, in the beginning of the experiment. That is to say that the biodegradation of the polymer itself does not have this degradation rate. This is supported by the fact that after 3 days and until 22 days no major changes in weight loss were observed. The high porosity and interconnectivity of the SPLA matrix prepared helps to understand this behaviour. The scaffold presents a maximum water uptake that is reached after 3 days of immersion. The diffusion of water into the bulk of the matrix weakens the structure, which is susceptible to a faster degradation. However, after this period no major changes were observed in the swelling and in the weight loss of the polymer within the time range analysed.

One of the effects of polymer hydrolysis is the change in the acidity of the media. Fig. 7 represents the trend of the $\mathrm{pH}$ of the media as polymer degradation occurs.

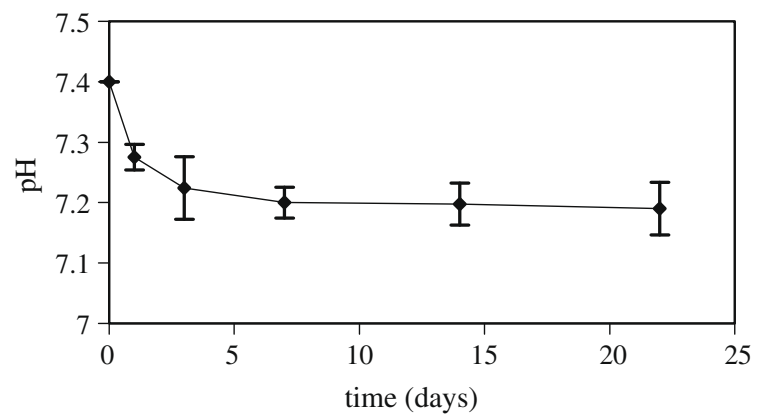

Fig. 7. $\mathrm{pH}$ profile of the isotonic solution where the SPLA 50:50 porous scaffolds, prepared by supercritical phase inversion $\left(200\right.$ bar and $\left.55^{\circ} \mathrm{C}\right)$ were immersed.
The $\mathrm{pH}$ of the solution decreases with time from 7.4 to 7.19. The knowledge and the control of the $\mathrm{pH}$ of the solution are important when we are considering the matrix for drug release purposes. The solubility of a drug in an aqueous environment is dependent on the $\mathrm{pH}$ of the solution, thus drug release rate will also vary according to this parameter. However, the effect of polymer degradation on the acidity of the solution is, in this case, and for the period of time of this study (22 days), not significant.

\subsection{In vitro release studies}

For tissue engineering of bone from stem cells, medium composition can guide differentiation along the ostogenic lineage. Glucocorticoids, such as dexamethasone, are added routinely in osteogenic medium as they are shown to have stimulatory effects on skeletal cells. It has also been suggested that the exposure of stem cells to dexamethasone may be effective in inducing and maintaining the osteoblastic phenotype [59-61]. The precise control of the drug release from the composite scaffolds prepared is the main goal of the systems prepared. In Fig. 8, the release of dexamethasone from the SPLA scaffolds is shown.

The profile is very similar for the three concentrations studied, as it would be expected since the polymeric matrix, which gives support to the drug, is the same. The release of drug from the scaffolds loaded with 10 and $15 \mathrm{wt} . \%$ of dexamethasone tends to the same value and a possible explanation for this might be the poor solubility of the drug in aqueous media.

In the case of the SPLA scaffolds loaded with 5wt.\% dexamethasone, one can observe from the release profile that, in fact, nearly $8 \mathrm{wt} . \%$ was impregnated. This might point to a drawback of the process for lower drug concentrations. The distribution of the drug within the matrix was not homogeneous and therefore the percentage of drug impregnated was found to be higher than that expected from the calculation of the theoretical amount.

Usually, conventional drug delivery products provide sharp increases in the drug concentration at potentially toxic levels, followed by a relatively short period at the therapeutic level and drug concentration drops until new administration. In controlled drug delivery systems designed for long-term administration, the drug level should ideally follow a profile similar to the one shown in Fig. 8. From the release experiments we can conclude that a sustainable release of dexamethasone from the scaffolds was achieved for periods over 21 days.

Dexamethasone activity as an inductive agent in osteogenic culture systems is relevant. Several studies in the literature report the in vitro osteogenic differentiation of purified, culture-expanded human MSCs, therefore the preparation of a scaffold able to release an active agent at a controlled rate, with the appropriate concentration, is important.

Fig. 9 presents the drug release profile of drug in terms of the percentage of dexamethasone release as a function of 


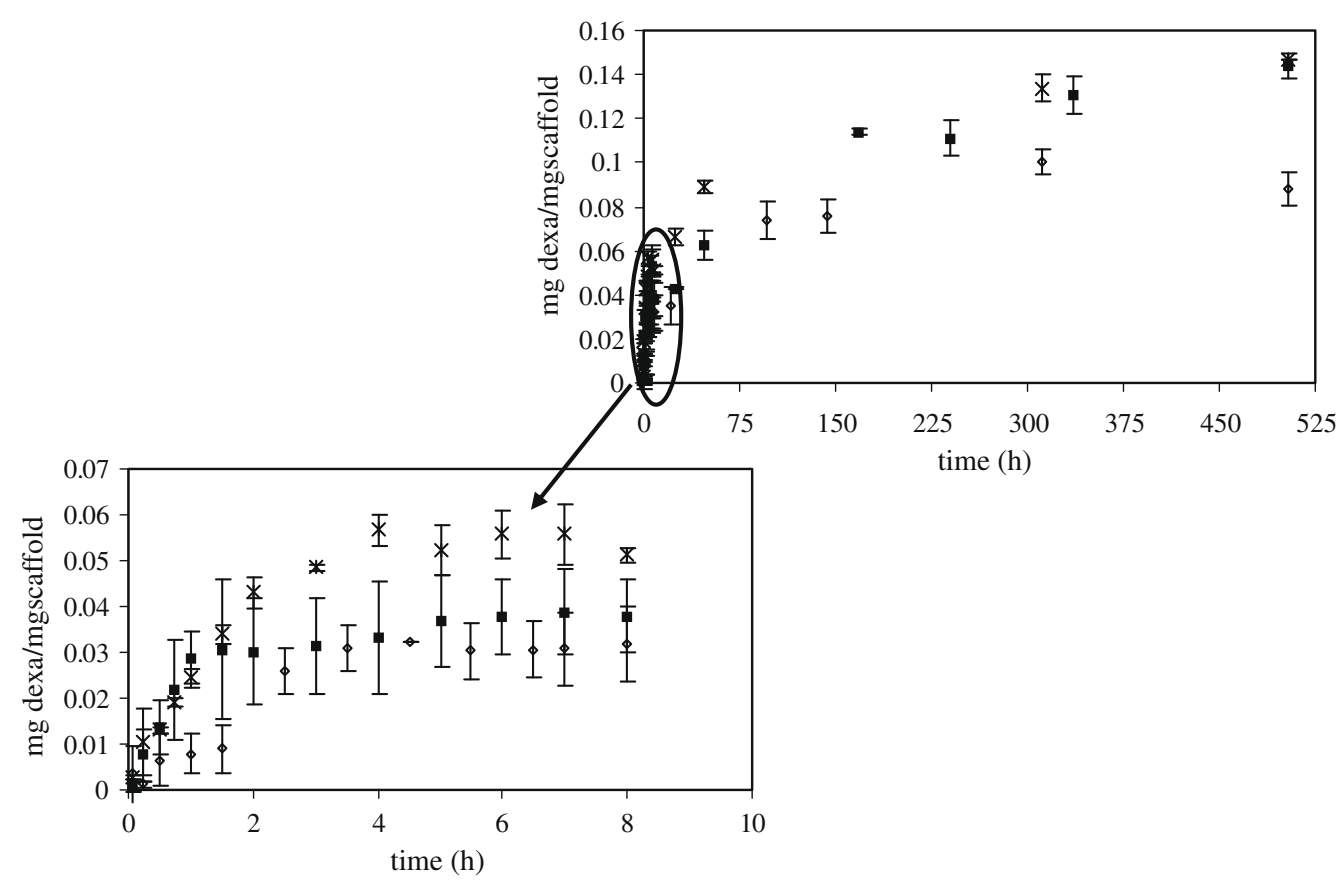

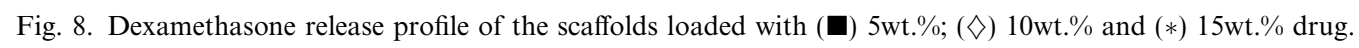

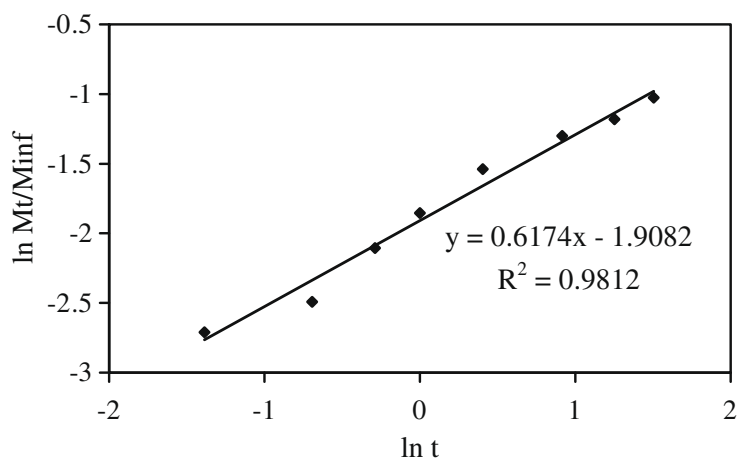

Fig. 9. Percentage of drug release as a function of time for the system with

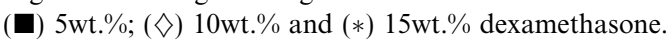

time. For all the three compositions studied, the trend is very similar as can be observed. As can also be observed from the figure, after 21 days around $80 \%$ of the drug was released.

To better understand the drug release mechanism of the systems prepared the power law was applied to the experimental data. Power law is a simple empirical equation (see Eq. (4)), which describes a linear relationship between logarithm of the percentage of drug released and logarithm of time, up to $60 \%$ of the maximum drug released [51].

Fig. 10 shows, as an example, the linear fit of the log-log data related to the release profile of the sample prepared with $15 \mathrm{wt} . \%$ of dexamethasone.

The correlation coefficient of the regression was 0.95 , meaning that the power law is adequate to describe the mechanism of drug release from the SPLA scaffolds.

From the fit of Eq. (4) to the experimental data obtained after the in vitro release studies it is possible to calculate the

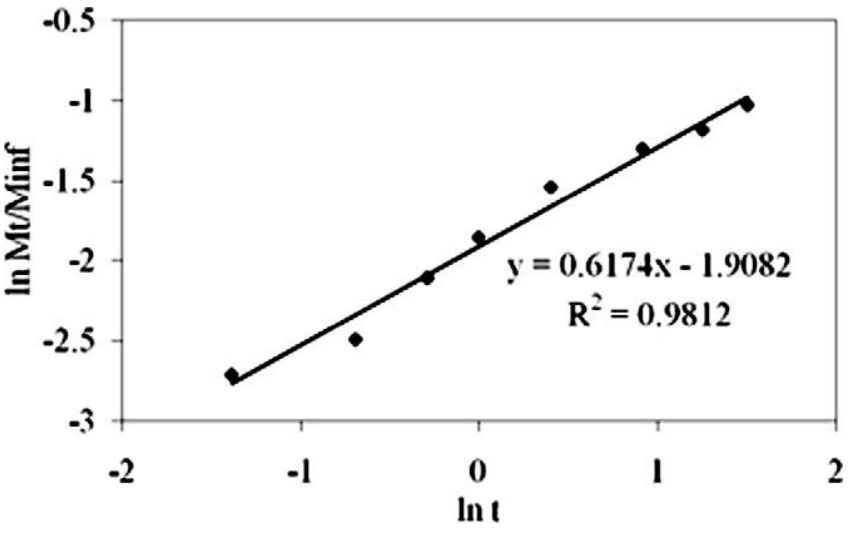

Fig. 10. Power law applied to the drug release profile of the SPLA samples loaded with $15 \mathrm{wt} . \%$ of dexamethasone.

kinetic parameters that describe the early stage mechanism underlying this delivery system. The release exponent $n$, indicative of the mechanism of the drug release, was calculated from the slope of the curve. Additionally, from the power law it is also possible to derive the kinetic constant of the system, which is characteristic of properties of the matrices prepared as it incorporates the structural and geometrical characteristics of the device. The results obtained for the three samples are presented in Table 1.

Table 1

Kinetic parameters calculated from the fit of the power law to the experimental data of drug relase profiles

\begin{tabular}{lll}
\hline Sample & Release exponent, $n$ & Kinetic constant, $k$ \\
\hline SPLA:dex $5 \mathrm{wt} \%$ & 0.62 & 0.11 \\
SPLA:dex $10 \mathrm{wt} \%$ & 0.63 & 0.12 \\
SPLA:dex $15 \mathrm{wt} \%$ & 0.62 & 0.14 \\
\hline
\end{tabular}


Two mechanisms control the drug release rate from polymeric devices: Fickian diffusion and the so-called case-II transport. Fickian diffusional release occurs by the usual molecular diffusion of the drug due to a concentration gradient. Case-II transport is the mechanism associated with the relaxation process of the macromolecules upon water uptake into the polymeric matrix. From the power law (Eq. (4)), it is possible to conclude that when the release exponent is 1 the drug release corresponds to a zero-order kinetic. In this case, and for a thin film sample the governing drug release mechanism is the case-II transport. Another special case is when the release exponent is 0.5 , which indicates diffusion-controlled drug release. When calculated $n$ values are between 0.5 and 1 a superposition of both phenomena (diffusional and relaxational release) occurs and in these cases the mechanism that governs the drug release is called an anomalous transport. The power law release exponents calculated from our experiments indicate that the dexamethasone release from the SPLA scaffolds is governed by an anomalous transport, meaning that both diffusion of the drug out of the matrix and the water uptake and swelling of the polymeric matrix influence the drug release.

\section{Conclusions}

This work evaluated the feasibility of preparing drugloaded porous structures of natural based polymeric systems using a supercritical-assisted phase inversion method.

The loaded SPLA matrices obtained by supercriticalassisted phase inversion are bicontinuous structures characterized by a rough surface where micropores and macropores are present. The same type of structures was obtained for the unloaded SPLA scaffolds, meaning that the presence of dexamethasone did not alter the morphology of the three-dimensional scaffolds. Different concentrations of dexamethasone were loaded in SPLA 50:50 scaffolds. From the release profiles we can conclude that dexamethasone release can be sustained for over 21 days and the modelling of the drug release experimental data indicates that the release is governed by an anomalous transport, which comprises not only drug diffusion but also the water uptake of the polymeric matrix.

The preparation of scaffolds loaded with a pharmaceutical agent for tissue engineering purposes using supercriticalassisted phase inversion has proven to be feasible and a onestep process was carried out with no need for further drying processes. We believe that such methodology could be adapted to prepare porous structures using other natural based polymeric systems and other bioactive compounds.

\section{Acknowledgment}

Ana Rita C. Duarte is grateful for financial support from Fundação para a Ciência e Tecnologia through the Grant SFRH/BPD/34994/2007.

\section{References}

[1] Liu X, Ma PX. Polymeric scaffolds for bone tissue engineering. Ann Biomed Eng 2004;32(3):477.

[2] Hutmacher DW, Schantz JT, Lam CXF, Tan KC, Lim TC. State of the art and future directions of scaffold-based bone engineering from a biomaterials perspective. J Tissue Eng Regen Med 2007;1:245-60.

[3] Malafaya PB, Silva GA, Baran ET, Reis RL. Drug delivery therapies I: general trends and its importance on bone tissue engineering applications. Curr Opin Solid State Mater Sci 2002;6(4):283-95.

[4] Malafaya PB, Silva GA, Baran ET, Reis RL. Drug delivery therapies II: strategies for delivering bone regenerating factors. Curr Opin Solid State Mater Sci 2002;6(4):297-312.

[5] Gomes ME, Reis RL. Biodegradable polymers and composites in biomedical applications from catgut to tissue engineering. Part I: available systems and their properties. Int Mater Rev 2004;49(5): 261-73.

[6] Gomes ME, Reis RL. Biodegradable polymers and composites in biomedical applications from catgut to tissue engineering. Part II: systems for temporary replacement and advanced tissue regeneration. Int Mater Rev 2004;49(5):274-85.

[7] Habibovic P, de Groo K. Osteoinductive biomaterials-properties and relevance in bone repair. J Tissue Eng Regen Med 2007;1:25-32.

[8] Green D, Walsh D, Yang X, Mann S, Oreffo ROC. Stimulation of human bone marrow stromal cells using growth factor encapsulated calcium carbonate porous microspheres. J Mater Chem 2004;14: 2206-12.

[9] Eroglu H, Kas HS, Oner L, Turkoglu OF, Akalan N, Sargon MF, et al. The in-vitro and in-vivo characterization of PLGA:L-PLA microspheres containing dexamethasone sodium phosphate. J Microencapsul 2001;18:603-12.

[10] Yoon JJ, Kim JH, Park TG. Dexamethasone-releasing biodegradable polymer scaffolds fabricated by a gas-foaming/salt-leaching method. Biomaterials 2003;24:2323-9.

[11] Mano JF, Silva GA, Azevedo HS, Malafaya PB, Sousa RA, Silva SS, et al. Natural origin biodegradable systems in tissue engineering and regenerative medicine: present status and some moving trends. J Royal Soc Int 2007;4(17):999-1030.

[12] Dang JM, Leong KW. Natural polymers for gene delivery and tissue engineering. Adv Drug Del Rev 2006;58:487.

[13] Malafaya PB, Silva GA, Reis RL. Natural-origin polymers as carriers and scaffolds for biomolecules and cell delivery in tissue engineering applications. Adv Drug Del Rev 2007;59(4-5):207-33.

[14] Salgado AJ, Coutinho OP, Reis RL, Davies JE. In vivo response to starch based scaffolds for bone tissue engineering applications. J Biomed Mater Res part A 2007;80(4):983-9.

[15] Ghosh S, Viana JC, Reis RL, Mano JF. The double porogen approach as a new technique for the fabrication of interconnected poly(L-lactic acid) and starch based biodegradable scaffolds. J Mater Sci Mat Med 2007;18(2):185-93.

[16] Ghosh S, Viana JC, Reis RL, Mano JF. Development of porous lamellar poly(L-lactic acid) scaffolds by conventional injection molding process. Acta Biomaterialia 2008;4(4):887-96.

[17] Silva GA, Costa J, Coutinho OP, Radin S, Ducheyne P, Reis RL. Synthesis and evaluation of novel bioactive composite starch/ bioactive glass microparticles. J Biomed Mater Res Part A 2004;70A:442.

[18] Boesel LF, Mano JF, Elvira C, San Roman J, Reis RL. Hydrogels and hydrophilic partially degradable bone cements based on biodegradable blends incorporating starch. In: Chiellini E, editor. Biodegradable polymers and plastics. Dordrecht: Kluwer; 2003.

[19] Boesel LF, Mano JF, Reis RL. Optimization of the formulation and mechanical properties of starch based partially degradable bone cements. J Mater Sci Mater Med 2004;15:73-83.

[20] Malafaya PB, Elvira C, Gallardo A, San Roman J, Reis RL. Porous starch-based drug delivery systems processed by a microwave treatment. J Biomater Sci Polym 2001;12(11):1227. 
[21] Malafaya PB, Stappers F, Reis RL. Starch-based microspheres produced by emulsion crosslinking with a potential media dependent responsive behavior to be used as drug delivery carriers. J Mater Sci Mater Med 2006;17:371-7.

[22] Silva GA, Costa FJ, Neves NM, Coutinho OP, Dias ACP, Reis RL. Entrapment ability and release profile of corticosteroids from starch based microparticles. J Biomed Mater Res part A 2005;73A(2):234 43.

[23] Fu Q, Rahaman MN, Dogan F, Bal BS. Freeze-cast hydroxyapatite scaffolds for bone tissue engineering applications. Biomed Mater 2008; 3(2).

[24] Sultana N, Wang M. Fabrication of HA/PHBV composite scaffolds through the emulsion freezing/freeze-drying process and characterisation of the scaffolds. J Mater Sci Mater Med 2008;19(7):2555-61.

[25] Nakamatsu J, Torres FG, Troncoso OP, Yuan ML, Boccaccini AR. Processing and characterization of porous structures from chitosan and starch for tissue engineering scaffolds. Biomacromolecules 2006;7(12):3345-55

[26] Ghosh S, Viana JC, Reis RL, Mano JF. The double porogen approach as a new technique for the fabrication of interconnected poly(L-lactic acid) and starch based biodegradable scaffolds. J Mater Sci Mater Med 2007;18(2):185-93.

[27] Neves NM, Kouyumdzhiev A, Reis RL. The morphology, mechanical properties and ageing behavior of porous injection molded starch-based blends for tissue engineering scaffolding. Mater Sci Eng C 2005;25(2):195-200.

[28] Gomes ME, Azevedo HS, Moreira AR, Ellä V, Kellomäki M, Reis RL. Starch-poly(e-caprolactone) and starch-poly(lactic acid) fibremesh scaffolds for bone tissue engineering applications: structure, mechanical properties and degradation behaviour. J Tissue Eng Regen Med 2008;2(5):243-52.

[29] Leonard A, Calberg C, Kerckhofs G, Wevers M, Jerome R, Pirard $\mathrm{JP}$, et al. Characterization of the porous structure of biodegradable scaffolds obtained with supercritical $\mathrm{CO}_{2}$ as foaming agent. J Porous Mater 2008;15(4):397-403.

[30] Tuzlakoglu K, Alves CM, Mano JF, Reis RL. Production and characterization of chitosan fibers and 3D fiber mesh scaffolds for tissue engineering applications. Macromol. Biosci. 2004;4:811-9.

[31] Martins A, Araújo JV, Reis RL, Neves NM. Electrospun nanostructure scaffolds for tissue engineering applications. Nanomedicine 2007;2(6):929-42.

[32] Hutmacher DW. Scaffold design and fabrication technologies for engineering tissues-state of the art and future perspectives. J Biomater Sci Polym 2001;12:107.

[33] Davies OR, Lewis AL, Whitaker MJ, Tai H, Shakesheff KM, Howdle SM. Applications of supercritical $\mathrm{CO}_{2}$ in the fabrication of polymer systems for drug delivery and tissue engineering. Adv Drug Del Rev 2008;60(3):373-87.

[34] Quirk RA, France RM, Shakesheff KM, Howdle SM. Supercritical fluid technologies and tissue engineering scaffolds. Curr Opin Solid State Mater Sci 2004; 8: 313

[35] Tomasko DL, Li H, Liu D, Han X, Wingert MJ, Lee LJ, et al. A review of $\mathrm{CO}_{2}$ applications in the processing of polymers. Ind Eng Chem Res 2003;42:6431.

[36] Davies OR, Lewis AL, Whitaker MJ, Tai H, Shakesheff KM, Howdle SM. Applications of supercritical $\mathrm{CO}_{2}$ in the fabrication of polymer systems for drug delivery and tissue engineering. Adv Drug Del Rev 2007;60(3):373.

[37] Cooper AI. Porous materials and supercritical fluids. Adv Mater 2003;15(13):1049.

[38] Kikic I, Sist P. Applications of supercritical fluids to pharmaceuticals: controlled drug release systems. In: Kiran E, Debenedetti PG, Peters CJ, editors. Supercritical fluids: fundamentals and applications proceedings of the 2nd NATO ASI on supercritical fluids. NATO science series. Dordrecht, Netherlands: Kluwer; 2000, p. 291.

[39] Tsivintzelis I, Pavlidou E, Panayiotou C. Porous scaffolds prepared by phase inversion using supercritical $\mathrm{CO}_{2}$ as antisolvent I. Poly(Llactic acid). J Supercrit Fluids 2007; 40: 317.
[40] Tsivintzelis I, Marras SI, Zuburtikudis I, Panayiotou C. Porous poly(L-lactic acid) nanocomposite scaffolds prepared by pahse inversion using supercritical CO2 as antisolvent. Polymer 2007;48:6311.

[41] Reverchon E, Cardea S, Rappo ES. Production of loaded PMMA structures using the supercritical $\mathrm{CO} 2$ phase inversion process. J Membr Sci 2006;273: 97-105.

[42] Kho YW, Kalika DS, Knutson BL. Precipitation of nylon 6 membranes using compressed carbon dioxide. Polymer 2001;42:6119.

[43] Matsuyama H, Yamamoto A, Yano H, Maki T, Teramoto M, Mishima K, et al. Formation of porous flat membranes by phase separation with supercritical $\mathrm{CO}_{2}$. J Membr Sci 2001;194:157.

[44] Matsuyama H, Yamamoto A, Yano H, Maki T, Teramoto M, Mishima K, et al. Effect of organic solvents on membrane formation by phase separation with supercritical $\mathrm{CO}_{2}$, J Membr Sci 2002; 204: 81.

[45] Reverchon E, Cardea S. Formation of cellulose acetate membranes using a supercritical fluid assisted process. J Membr Sci 2004;240:187.

[46] Reverchon E, Cardea S. Formation of polysulfone membranes by supercritical $\mathrm{CO}_{2}$. J Supercrit Fluids 2005;35:140.

[47] Temtem M, Casimiro T, Mano JF, Aguiar-Ricardo A. Preparation of membranes with polysulfone/polycaprolactone blends using a high pressure cell specially designed for a $\mathrm{CO}_{2}$-assisted phase inversion. $\mathbf{J}$ Supercrit Fluids 2008; 43: 542.

[48] Kim M-S, Lee S-J. Characteristics of porous polycarbonate membrane with polyethylene glycol in supercritical $\mathrm{CO}_{2}$ and effect of its porosity on tearing stress. J Supercrit Fluids 2004;31:217.

[49] Duarte ARC, Mano JF, Reis RL. Preparation of starch-based scaffolds for tissue engineering by supercritical immersion precipitation. J Supercritical Fluids. doi:10.1016/j.supflu.2008.012.008.

[50] Higuchi T. Rate of release of medicaments from ointment bases containing drugs suspension. J Pharm Sci 1961;50:874-5.

[51] Siempmann J, Peppas NA. Modelling of drug release from delivery systems based on hydroxypropyl methylcellulose (HPMC). Adv Drug Del Rev 2001;48:139-57.

[52] Ritger PL, Peppas NA. A simple equation for description of solute release I. Fickean and non-fickean release from non-swellable devices in the form of slabs, spheres, cylinders or discs. J Control Rel 1987;5:23-36.

[53] Ritger PL, Peppas NA. A simple equation for description of solute release II. Fickean and anomalous release from swellable devices. J Control Rel 1987;5:37-42.

[54] Neves MN, Kouyumdzhiev A, Reis RL. The morphology, mechanical properties and ageing behavior of porous injection molded starch-based blends for tissue engineering scaffolding. Mater Sci Eng C 2005;25(2):195-200.

[55] Ghosh S, Viana JC, Reis RL, Mano JF. Bi-layered constructs based on poly(L-lactic acid) and starch for tissue engineering of osteochondral defects. Mater Sci Eng C 2008;28(1):80-6.

[56] Gomes ME, Godinho JS, Tchalamov D, Cunha AM, Reis RL. Alternative tissue engineering scaffolds based on starch: processing methodologies, morphology, degradation and mechanical properties. Mater Sci Eng C 2002;20(1-2):19-26.

[57] Miroslav PP, Mano JF, Neves NM, Reis RL. Fibers and 3D mesh scaffolds from biodegradable starch-based blends: production and characterization. Macromol. Biosci. 2004;4:776-84.

[58] Ghosh S, Gutierrez V, Fernández C, Rodriguez-Perez MA, Viana JC, Reis RL, et al. Dynamic mechanical behavior of starch-based scaffolds in dry and physiologically simulated conditions: Effect of porosity and pore size. Acta Biomaterialia 2008;4(4):950-9.

[59] Jaiswal N, Haynesworth SE. Osteogenic differentiation of purified, cultured-expanded human mesenchymal stem cells in vitro. J Cell Biochem 1997;64(2):295-312.

[60] Maniatopolous C, Sodek J, Melcher AH. Bone formation in vitro by stromal cells obtained from one marrow of young adult rats. Cell Tissue Res 1988;254:317-30.

[61] Jaiswal N, Haynesworth SE, Caplan AI, Bruder SP. Osteogenic differentiation of purified, culture-expanded human mesenchymal stem cells in vitro. J Cell Biochem 1997;64:295-312. 